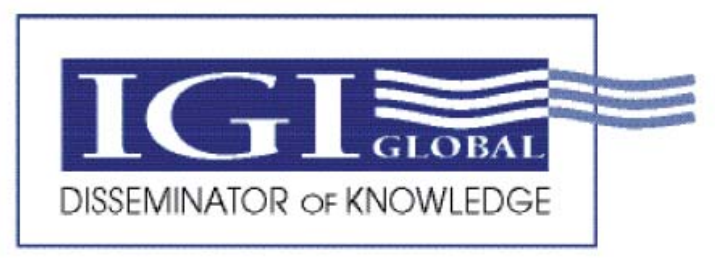

\title{
New Release: Internet Accessible Remote Laboratories
}

Hershey, PA - November 2, 2011 - Limited resources and other factors pose major challenges for engineering, technology, and science educators' ability to provide adequate laboratory experience for students. An Internet accessible remote laboratory, which is an arrangement that allows laboratory equipment to be controlled remotely, addresses these difficulties and allows more efficient laboratory management.

Edited by Abul K.M. Azad, Northern Illinois University, USA; Michael E. Auer, Carinthia University of Applied Sciences, Austria; and V. Judson Harward, Massachusetts Institute of Technology, USA, IGI Global's newest release, Internet Accessible Remote Laboratories: Scalable E-Learning Tools for Engineering and Science Disciplines collects current developments in the multidisciplinary creation of Internet accessible remote laboratories. This book offers perspectives on teaching with online laboratories, pedagogical design, system architectures for remote laboratories, future trends, and policy issues in the use of remote laboratories. It is useful resource for graduate and undergraduate students in electrical and computer engineering and computer science programs, as well as researchers who are interested in learning more about the current status of the field as well as various approaches to remote laboratory design.

Topics covered in Internet Accessible Remote Laboratories: Scalable E-Learning Tools for Engineering and Science Disciplines include, but are not limited to:

Collaborative Research on Remote Laboratories Educational Tools for Remote Laboratories Industrial Applications of Remote Laboratories Inter-Institutional Use of Remote Laboratories Pedagogical Design of Remote Laboratories Remote Laboratories and Ethical Concerns Sustainability of Remote Laboratories System Architectures for Remote Laboratories System Design, Hardware and Interfacing Teaching with Remote Laboratories

To learn more about IGI Global's newest release, please visit http://www.igi-global.com/book/internet-accessible-remote-laboratories/52730.

\section{Contact: Christine Bufton}

Director of Promotions \& Communications

Address: 701 E. Chocolate Ave., Hershey, PA 17033

Email: cbufton@igi-global.com

Tel.: +1 717-533-8845 x120

Fax: +1 717-533-8661

Web: www.igi-global.com

Order inquiries may be directed to: 717-533-8845 x100, to cust@igi-global.com, or to book wholesalers or journal subscription agents. 